\title{
World Café method integrated with QFD for obtaining the Voice of the Customer
}

\author{
Jair Gustavo de Mello Torres ${ }^{\mathrm{a} *}$, Pedro Luiz de Oliveira Costa Neto ${ }^{\mathrm{a}}$ \\ aniversidade Paulista, São Paulo, SP, Brasil \\ *jair_gustavo@yahoo.com.br
}

\begin{abstract}
Paper aims: Investigate the results of the use of the World Café method as a tool to assist the capture of the Voice of the Customer, in a curricular discipline that works with ABPj (Project-Based learning).

Originality: As the authors have not found in the literature the application of the World Café method integrated to QFD.

Research method: Teachers and the coordination of a logistics course worked together on the application of the method, following the five major phases of the action research, which are: diagnosis, planning, action, evaluation and learning.

Main findings: The method allowed to establish the most important personal characteristics needed to develop the pedagogical projects, from the point of view of the students.

Implications for theory and practice: The findings of this work can be used as a basis to understand how to engage students in pedagogical logistics projects.

Keywords

Quality function deployment. ABPj. Entrepreneurship. Prioritization.
\end{abstract}

How to cite this article: Torres, J. G. M., \& Costa Neto, P. L. 0. (2018). World Café method integrated with QFD for obtaining the Voice of the Customer. Production, 28, e20170097. https://doi.org/10.1590/0103-6513.20170097.

Received: Dec. 11, 2017; Accepted: Sept. 6, 2018.

\section{Introduction}

The capacity to promote self-development is one of the main roles reserved for education, whose purpose is to make each person assume his own destiny and contribute to the progress of the society in which he lives through the responsible participation of individuals and communities (Delors, 2006).

According to the same author, an effective education is based on four pillars of knowledge: 1) learning to know, that is to acquire the instruments of understanding; 2) learning to do, or to be able to act on the environment; 3) learning to live together, in order to participate and cooperate with others in all human activities; and finally 4) learning to be, which integrates the previous three. These four pillars of knowledge may be, in fact, only one, since there are multiple points of contact, relationship and exchange among them.

Productivity and the world of work require effective education outcomes that should make these four fundamental achievable throughout the life of each individual, but there are some widespread complaints from students in schools and universities, since they cannot more stand for the traditional teaching, which does not incorporate the many changes in society. Thus, it is necessary to reinvent the way of teaching and learning, creating and instituting new methods (Silva, 2003).

There are several learning methods that privilege the four pillars of knowledge defined by Delors (2006). One of these, Project Based learning (ABPj), is, to Kokotsaki et al. (2016), a student-centered teaching-learning method based on three basements of constructivism: learning is context-specific; students are actively involved in the learning process and students achieve their goals with social interactions and sharing knowledge and understanding. 
The utmost product of education is generally intangible and difficult to measure, according to Brian Hwarng \& Teo (2001), as it is reflected in the transformation of individuals, their knowledge, characteristics and behaviors. For Chang (2016), the selection of appropriate teaching tools can make a significant difference in learning performance.

A particular type of research-based learning in which the context of learning is provided through authentic questions and problems within real-world practices that lead to meaningful learning experiences is part of the approaches of Kokotsaki et al. (2016).

The World Café method by Brown \& lsaacs (2007) is anxious to answer this question. The authors recommend to conduct an in-depth exploration of basic challenges and opportunities, sharing knowledge, stimulating innovative thinking, building a community and exploring possibilities around real-life themes and issues. Teza et al. (2013) emphasize that the World Café method is based on the understanding that conversation is the central process that drives personal and organizational business. Chang (2016) states that many teachers involved in entrepreneurship training are implementing the World Café method to increase traditional classroom discussions.

Lefika \& Mearns (2015) found that The World Café is a very useful method for generating creative ideas or for building consensus. However, with regard to problem solving of a technical nature, knowledge cafes were less successful. They emphasize that the implementation of the results of The World Café can be difficult.

Cheng \& Melo Filho (2007) report that Quality Function Deployment (QFD) is a method used for project development focused on customer satisfaction and is guided by the following assumption: every project will succeed if and only if the customer is satisfied. Thus, the starting point for systematic deployment is the Voice of the Customer (needs and desires), because if satisfactorily met, there will be a good possibility of success. Therefore, it is important that organizations have the means to know the Voice of the Customer.

The most recent literature on QFD is marked by significant case growth in the service sector. There are several successful reports on the application of the method to banking institutions, hospitals, hotels, transport and education companies (Freitas et al., 2015).

Although QFD is a recognized methodology for increasing customer satisfaction based on your understanding of and to improve the design of services that meet or exceed customer expectations, some limitations are presented. Among the limitations, we can mention the need to deal with large amounts of data collected from customers, competitors and teams, the difficulty and slowness in evaluating the relationships between each of the client's requirements and service characteristics, as well as the correlations between the various characteristics of the service and the voice of the client contain different ambiguities and meanings due to the fact that not all have the same perception of a special linguistic description (Souza \& Cauchick Miguel, 2017).

Souza \& Cauchick Miguel (2017) point out that in the face of these limitations presented by QFD, several authors use other methodologies and tools to fill these gaps. According to Freitas et al. (2015), the most recent empirical work has sought to propose new methodologies that combine the method with quantitative and qualitative tools such as: Analytical Hierarchy Process (AHP), Fuzzy Logic, statistical techniques), Kano Model and model SERVQUAL.

Despite the extensive bibliography of the use of the QFD method in conjunction with other auxiliary tools, the authors did not find a joint application of the QFD methods and the World Café. Faced with this research gap, the main objective of this article is to analyze the results of using the World Café method as a tool to aid in the capture of the Voice of the Client.

As a way of delimiting the application scope of the method, the present work aims to investigate the results of the use of the World Café method as a tool to assist the capture of the Voice of the Customer (in this case the students), to analyze which personal characteristics are most important to develop the pedagogical projects of a Logistics course, from the point of view of the students, in a curricular discipline that works with $A B P j$ (Project-Based learning).

\section{Theoretical framework}

\subsection{Quality function deployment}

The QFD method is presented by Costa Neto \& Canuto (2010) as a system based on input and output matrices that allow transforming the desires of customers into design, process service and product requirements.

The QFD, according to Cheng \& Melo Filho (2007), can also be conceptualized as a tool to systematically communicate in an orderly way what information indicates the related work to reach the desired quality and aims 
to reach the quality assurance focus during the development and is subdivided into Quality Deployment (QD) and Quality Deployment in the restricted sense (QFDr).

The aforementioned authors conceptualize the Quality Deployment (QD) as the process that seeks to translate and transmit customer requirements into product quality characteristics through systematic unfolding, starting with the determination the Voice of the Customer, passing through the establishment of functions, mechanisms, components, processes, raw materials and extending to the establishment of process control parameter values.

They also define the QFDr as Work Function Deployment or, simply, Work Deployment. The purpose of QFDr is to accurately specify what functions or human work are required to achieve product and company quality that meet customer needs. QFDr contributes to the preparation of two important documents of the Quality Assurance System of the Company: the Quality Assurance System Diagram (DSGQ) and the Quality Assurance Activity Table (TAGQ).

Although QFD is a recognized methodology to increase customer satisfaction in products and services based on understanding their needs and to improve the design of services that meet or exceed their expectations, Souza \& Cauchick Miguel (2017) consider that some limitations are presented in the method and show in their studies that QFD can also be combined with other methodologies and tools in a complementary way, in order to require flexibility and thus to attend different situations, not limited to one type of solution. This flexibility is demonstrated through the incorporation of other tools that bring the possibility of adapting the answers to the specific problems and in line with the wishes of those involved.

The selection of auxiliary technique to QFD to obtain the most appropriate Voice of the Customer depends on the desired information and available budget. Qualitative techniques are the most appropriate at this stage, as they allow the generation of ideas and the deepening of the user's point of view about the product. The main goal is to produce a list of needs that be as wide as possible, with the mind free of preconceived ideas, seeking to learn, simply listening and observing the clients (Cheng \& Melo Filho, 2007).

\subsection{World Café}

The World Café method is conceptualized by Brown \& lsaacs (2007) as a simple but yet powerful process of conversation to promote constructive dialogue, access to collective intelligence and creation of innovative possibilities for action, particularly in groups that are larger than those for which most traditional approaches to dialogue are designed to settle. It is also found in literature as Coffee of Knowledge, Coffee of Leadership, Quality Café, and Coffee of Strategies, among other designations.

According to Kempnich \& Costanzo (2014), the World Café format offers a way for the creative process to emerge and give depth to participants' responses, as a structured methodology for dialogue and conversation among them, which includes an important assumption: that participants already have same experience and knowledge in their minds, as a kind of tacit knowledge.

Brown \& lsaacs (2007) point out that a World Café dialogue sets the stage for more traditional forms of action planning, which often take place during the same session, but at a later instant in time.

The methodology presents seven fundamental principles, namely:

1. Establish the context;

2. Create a welcoming space;

3. Explore meaningful issues;

4. Stimulate the contribution of all;

5. Promote cross-pollination and connect different points of view;

6. Listen together to discover patterns, perceptions and deeper issues;

7. Collect and share collective discoveries.

Kempnich \& Costanzo (2014) argue that the outcome of the World Café includes a robust summary of responses to questions that can be categorized and used for interventions within action plans for initiatives. Brown \& lsaacs (2007) reinforce that a World Café dialogue sets the stage for more traditional forms of action planning.

Brown \& lsaacs (2007) explain that the dynamics of the World Café take place in the following way: the participants are distributed in tables, with up to five members, and each table elects a Host. Then the first round 
begins. At the end of the round, the Host remains at the table and the others go to other tables. The Host then synthesizes the ideas discussed before for the new members of the table and begins new discussions begin. In the third final round, the participants return to the table of origin. The Host explains what was discussed in the previous rounds and, after a moment of reflection by the group, a space for new discussion is opened. From this discussion are registered the main ideas raised by the whole group.

For Lagrosen (2017) the World Café has proved to be useful as a qualitative research method to explore the views of many people in order to create value that is truly meaningful. Teza et al. (2013) used the World Café method in two classes of young apprentices, aiming the generation of ideas for an event according to the theme proposed by the educational institution. Kempnich \& Costanzo (2014) used it in planning new approaches in leadership development within a graduate nursing curriculum. Chang \& Chen (2015) compared the World Café with conventional strategy workshops with respect to enhancing strategic planning capability in face-to-face business plan training in Taiwan. Broom et al. (2013) used the World Café during the design process for a Neonatal Intensive Care Unit project. Barbosa \& Hoffmann (2013) used the method to evaluate the forms of support more attractive for the admission into an incubation process and for the consolidation of companies in a technology incubator. Yankeelov et al. (2018) examined the implementation and outcomes associated with community engagement method of World Café, which was instrumental in the development of a "culture of health" to reduce inequalities related to diabetes in the elderly in rural counties in Kentucky.

\subsection{World Café method integrated with QFD}

It is noteworthy that the scientific reports of applications of the World Café method integrated to QFD are non-existent. An analysis of the publications available in the Web of Science, Scopus, EBSCO and JStor databases, using the keywords: World Café contained in titles, together with the expression: Quality Function Deployment or QFD, present in any part of the text, indicated the lack of empirical work on applications of the World Café method integrated with QFD.

In a second analysis of the publications available in the Web of Science, Scopus, EBSCO and JStor databases, changing the keywords for "World Café" contained in titles, together with the expression "Quality Café", present anywhere of the text, indicated the existence of three empirical works. Only articles published in periodicals that reported the integration of the World Café method with quality management tools were considered.

Lagrosen (2017) examined the possibility of integrating the World Café method with the quality management affinity diagram tool. The proposed combination is called Quality Cafe. The method has been tested empirically in connection with several projects. The first and the largest was as part of an important study of quality and marketing in the Swedish spa industry. In this context, five Quality Cafés were held in 2012 and two in 2013 with employees in different hotels. The purpose of these cafes was to explore quality and health in the workplace in the spa industry. Later, the method was used in a meeting involving business and public sector leaders in a municipality in western Sweden in 2016. In this case, the goal was to find ways to increase the attractiveness of the municipality. Finally, in 2016, a Quality Café was held with members of the boards of two student organizations. This time, the goal was to come up with a suggestion for a mission statement for the university in which the organizations are active.

For Lagrosen (2017), the World Café and quality management tools have the ambition to contribute to deep learning in organizations. Quality management is a field in which a number of learning and innovation tools have been created. There are certain similarities between Quality Café and some of the traditional quality management tools, such as quality circles, the seven quality control tools, and the seven management tools. The most obvious difference is that while traditional quality management tools involve a very limited number of people in each activity, Quality Cafe is a method for gaining insights from a large number of people.

Therefore, in spite of the extensive bibliography on the use of the QFD method in conjunction with other auxiliary tools, the authors did not find a joint application of the QFD and World Café methods. In view of this research gap, the main objective of this article is to analyze the results of the use of the World Café method as a tool to aid in the capture of the Voice of the Customer.

\section{Methodology}

According to Cervo \& Bervian (2002), research can be classified by its nature, its approach, the character of the objective, and technical procedures. As to its nature, this is an applied work, that is, it has the generated knowledge resulting from a practical problem. Regarding the approach, this work can be classified as qualitative and quantitative. As for the objective, it can be classified as exploratory, since, from the bibliographic survey 
of the QFD method and the realization of the World Café, a better understanding of a specific problem related to the area of project development is sought. In relation to technical procedures, this is an action research, because the problem investigated was conducted by the first author, who has acted in the planning and control of its development.

Action research is a type of empirically based social research that is conceived and carried out in close association with an action or with the resolution of a collective problem. In action research, their conductors play an active role in addressing the problems which appear and also in monitoring and evaluating the actions suggested by the problems (Thiollent, 1986).

In this study, teachers and the coordination of a Logistics course worked together on the application of the method, following the five major phases of the action research proposed by de Freitas et al. (2015), which are: diagnosis, planning, action, evaluation and learning, as shown in Figure 1.

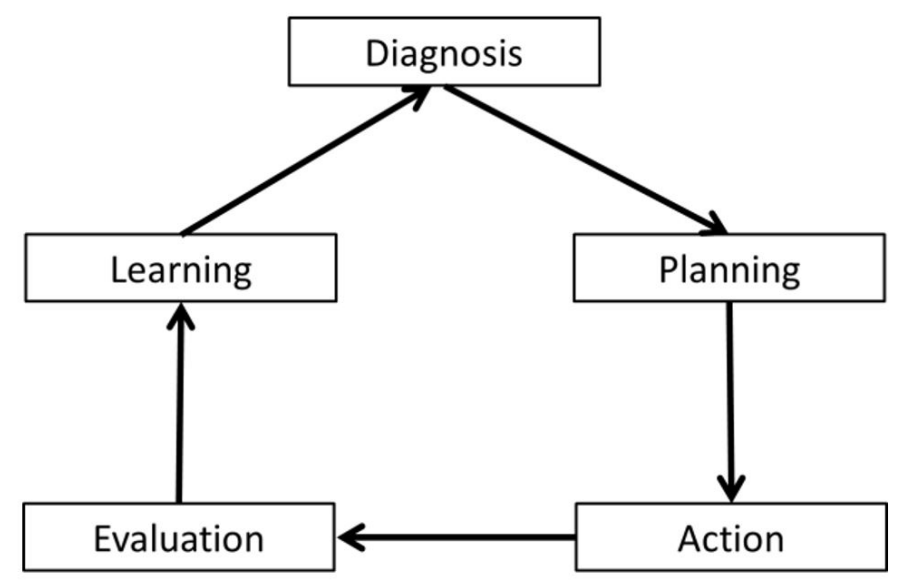

Figure 1. Methodological approach. Source: Adapted from de Freitas et al. (2015).

A wide bibliographic review of the QFD method and the World Café procedure was carried out, which was used as an auxiliary technique to the QFD for a process of generating ideas for the students' pedagogical projects. The authors, who have inducted the method, also investigated the personal characteristics of the students required to carry out the course projects.

\subsection{Diagnosis}

In the diagnostic phase, was chosen a group of students from a Logistics course in a secondary technical school enrolled in a curricular discipline that works with the methodology of Project-Based Learning (ABPj). The discipline of projects aims to offer students the opportunity to develop pedagogical projects based on their needs and interests. The study was conducted in April 2017.

\subsection{Planning}

In the planning phase, the conceptual model was initially elaborated using a logic of questions on "WHAT" should be achieved and "HOW" to obtain the results. Subsequently, the "HOW" returned was transformed into "WHAT" in subsequent rounds, in a cascade process, until the goal was achieved. The process of obtaining the Voice of the Customer involved the participation of the 32 students of the logistics course, who were the clients of the QFD method, and used the World Café method for data collection.

Cheng \& Melo Filho (2007) emphasize that the selection of the most appropriate technique for obtaining the information depends on the information desired and the available budget. Qualitative techniques are the most appropriate at this stage of development, as they allow the generation of ideas and the deepening in the point of view of the user of the product. 
The World Café method, according to Lefika \& Mearns (2015), is easy to implement and can be run on a low budget. Because it does not require a large investment for implementation, it becomes an economic way of sharing knowledge.

\subsection{Data collection}

The data collection phase was carried out in a project discipline class that lasted 3 hours. A timetable for the implementation of the World Café was established: 30 minutes for presentation of the method; 2 hours and 15 minutes for the execution of the rounds and 15 minutes for discussion of the results and closure.

The initice presentation is made to ensure participants to understand the rules of the World Café method, as well as the characteristics of a Host. It was explained that eight groups with four members would be formed freely and that each group should elect a Host from among the members. This Host would be fixed in the group and have the responsibility of synthesizing discussed ideas for the new members arriving in each round. Students were given three questions to ask during the activity, and each question would have three rounds for discussion. Each group received a flip chart sheet and colored pens to register each round results.

One of the principles of the World Café is the establishment of issues that have signification for the members of the participating groups. Each question had three rounds of fifteen minutes each for its discussion. The questions were:

Question 1: What are the needs of the population that Logistics can meet?

Question 2: What business opportunities can we create with Logistics in our region?

Question 3: What personal characteristics are needed to implement these solutions?

Then began the first round, referring to the first question. At the end of the round, the Host remained in the group and the others turned to other groups. The Host then synthesized the ideas discussed for the new members of the group and started new discussions. In the third round, the participants returned to the original group. The Host explained what was discussed in the previous rounds and, after a moment of reflection by the group, a space for new discussion was opened. From this discussion were registered the main ideas.

The procedure was repeated for the other two questions. At the end of the class, an analysis was made by the teacher along with the students of the dynamics and results obtained with the World Café procedure.

\section{Treatment of data and results}

In this item, it is presented how the results obtained by the application of the World Café were used as input data for the application of QFD, making the role of what, in circumstances more related to a consumer market, would represent the Voice of the Customer.

The data obtained in the World Café talks were analyzed by the group, wich classified them in sets according to their affinities, giving to each set a title representing that set. For the present article, as an illustration, only the data resulting from question 3 are presented. In total, twenty-two needs were identified, which compose the table of demanded qualities and appear in the closed questionnaire for subsequent prioritization.

The elaboration of the closed questionnaire consisted of using the data obtained in the World Café talks with the objective of capturing, according to the student's points of view, the importance of each item resulting from the questions of the World Café. The closed questionnaire was applied twenty days after the execution of the data collection phase, with 28 students, because four of them were in that day absent from the class.

The QFD method applied was the model proposed by Ribeiro et al. (2001). According to these authors, an importance index referring to each demanded quality is calculated by Equation 1:

$I D i^{*}=I D i \cdot \sqrt{E i} \cdot \sqrt{M i}$

where: $1 \mathrm{Di}^{*}=$ prioritization of quality items demanded; $1 \mathrm{Di}=$ importance of the quality items demanded; $\mathrm{Ei}=$ strategic evaluation; $\mathrm{Mi}=$ competitive evaluation .

The importance of the items that make up the demanded quality (IDi) is defined by the clients when filling out the closed questionnaire with direct questions that assign an importance value to each item according to 
their opinion. A scale from 1 to 10 ( 1 and 2, unimportant; 3 and 4, few important; 5 and 6, indifferent; 7 and 8, important; and 9 and 10, very important) was used.

According to Ribeiro et al. (2001), the degrees of importance attributed by customers to items of demanded quality should be expressed in percentages. This procedure ensures that so each block will have its weight correctly assigned.

The strategic evaluation of quality demand items (Ei) was carried out in conjunction with the coordination of the courses. All the quality items were evaluated considering the most important aspects of the pedagogical strategy of the teaching institution to be worked with the students. A scale of 0.5 to 2.0 ( 0.5 , small importance; 1.0, medium importance; 1.5 , large importance; and 2.0, very large importance) was used.

The items of quality demanded also consider a competitive evaluation (Mi), where the situation of the institution compared to the competitors was analyzed. In this case study, a scale of 0.5 to 2.0 was used (0.5, above the competition; 1.0, similar to the competition; 1.5, below the competition; and 2.0, far below the competition).

Table 1 lists the 22 personal characteristics that, according to the students, are necessary for the development of the pedagogical projects of the discipline. The characteristics were obtained through the application of the World Café and the affinity analysis of the answers to question 3: What personal characteristics are needed to implement these solutions?

Table 1. Calculation of the prioritization of quality items demanded (IDi*).

\begin{tabular}{|c|c|c|c|c|}
\hline Demanded Quality & IDi & $\mathrm{Ei}$ & $\mathrm{Mi}$ & $1 \mathrm{Di}^{*}$ \\
\hline Focus & 4.78 & 2.0 & 1.5 & 8.28 \\
\hline Knowledge search & 4.71 & 2.0 & 1.0 & 6.66 \\
\hline Entrepreneurship & 4.26 & 2.0 & 1.5 & 7.38 \\
\hline Organization & 4.69 & 2.0 & 1.5 & 8.12 \\
\hline Honesty & 4.69 & 2.0 & 1.0 & 6.63 \\
\hline Unity & 4.59 & 2.0 & 1.0 & 6.49 \\
\hline Humility & 4.17 & 0.5 & 1.0 & 2.95 \\
\hline Leadership & 4.15 & 2.0 & 1.5 & 7.19 \\
\hline Communication & 4.74 & 2.0 & 1.0 & 6.70 \\
\hline Group work & 4.84 & 2.0 & 1.0 & 6.84 \\
\hline Developing people & 4.24 & 1.0 & 1.5 & 5.19 \\
\hline Creativity & 4.72 & 2.0 & 0.5 & 4.72 \\
\hline Planning & 4.80 & 2.0 & 1.0 & 6.79 \\
\hline Effort & 4.78 & 2.0 & 0.5 & 4.78 \\
\hline Good relations / networking & 4.35 & 2.0 & 1.5 & 7.53 \\
\hline Agility & 4.20 & 1.5 & 1.5 & 6.30 \\
\hline Daring & 4.07 & 2.0 & 0.5 & 2.88 \\
\hline Persuasion & 4.37 & 2.0 & 1.0 & 6.18 \\
\hline Commitment & 4.85 & 2.0 & 0.5 & 4.85 \\
\hline Believe & 4.87 & 1.5 & 0.5 & 4.22 \\
\hline Proactivity & 4.54 & 2.0 & 0.5 & 4.54 \\
\hline Search for support & 4.59 & 2.0 & 1.0 & 6.49 \\
\hline
\end{tabular}

Source: Prepared by the authors.

The importance of the items of the demanded quality (IDi), as a result of the application of the closed questionnaire, shows that the most important characteristic for the development of pedagogical projects, in the students' opinion is, "Believe", with IDi $=4.87$, followed by "Commitment", with IDi $=4.85$, "Group work", with $\mathrm{IDi}=4.84$, and "Planning", with $\mathrm{IDi}=4.80$.

When the strategic evaluation (Ei) and the competitive evaluation (Mi) are used to calculate the priorite quality demanded items (IDi*), the most important characteristic for the development of pedagogical projects according to the QFD method is "Focus", with $\mathrm{IDi}^{*}=8.28$, followed by "Organization", with $1 \mathrm{Di}^{*}=8.12$, Good relations / networking “, with $\mathrm{IDi}^{*}=7.53$, and" Entrepreneurship “, with $\mathrm{IDi}^{*}=7.38$.

Then quality characteristics were established by listening to the coordination of the courses. The quality characteristics are measurable aspects that evaluate the quality of the product or service. In this study, it was established that the characteristics of quality were the ten characteristics of entrepreneurial behavior. Also called entrepreneurship skills, according to Lizote \& Verdinelli (2014), they are used as a model by the United Nations 
Development Program (UNDP) and also by the Small Business Support Service (SEBRAE) for entrepreneurship training programs, such as the Program for Entrepreneurs and Future Entrepreneurs (EMPRETEC).

These ten characteristics of entrepreneurial behavior listed by the mentioned authors are: search for opportunity and initiative; persistence; take calculated risks; requirement of quality and efficiency; commitment; search for information; setting goals; systematic planning and monitoring; persuasion and a network of contacts; independence and self-confidence.

The demanded quality relationship with the above entrepreneurial skills complements the QFD Quality Matrix. The intensity of the relationship between the items of the demanded quality (1Di*) and the entrepreneurial skill (DQij) was measured using the scale of 1 to 9 (1, weak; 3, medium; 9, strong). Table 2 shows the result of the demanded quality relationship step with the quality characteristics.

Table 2 . The result of the demanded quality relationship step with the quality characteristics.

\begin{tabular}{|c|c|c|c|c|c|c|c|c|c|c|}
\hline & 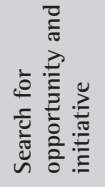 & 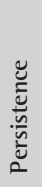 & 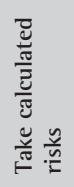 & 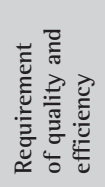 & 这 & 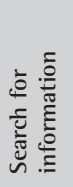 & 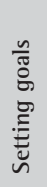 & 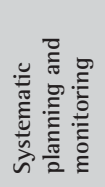 & 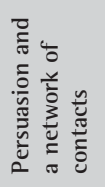 & 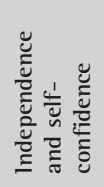 \\
\hline Focus & 9 & 9 & 3 & 3 & 3 & 9 & 9 & 9 & 3 & 9 \\
\hline Knowledge search & 3 & 3 & 9 & 3 & & 9 & 9 & 9 & 3 & 3 \\
\hline Entrepreneurship & 9 & 9 & 9 & 9 & 9 & 9 & 9 & 9 & 9 & 9 \\
\hline Organization & 3 & 3 & 3 & 9 & 3 & 3 & 9 & 9 & 3 & 3 \\
\hline Honesty & & & & 3 & 3 & & 1 & & 3 & 3 \\
\hline Unity & & & & & 9 & & & & 9 & 3 \\
\hline Humility & & & & & 9 & 9 & 1 & & 3 & 1 \\
\hline Leadership & 9 & 3 & 3 & & 9 & 3 & 9 & 1 & 9 & 9 \\
\hline Communication & 9 & 3 & 1 & & 3 & 3 & 3 & 1 & 9 & 9 \\
\hline Group work & 3 & & & & 9 & 3 & & 1 & 9 & 9 \\
\hline Developing people & & & & & 9 & & 1 & & 9 & 3 \\
\hline Creativity & 9 & 9 & 3 & & & 3 & 3 & & 3 & 3 \\
\hline Planning & 9 & 9 & 9 & 9 & 3 & 3 & 9 & 9 & 3 & 9 \\
\hline Effort & 9 & 9 & 3 & 9 & 9 & 9 & 9 & 9 & 3 & 9 \\
\hline Good relations / networking & 9 & 3 & 1 & & 3 & 9 & 3 & & 9 & 3 \\
\hline Agility & 9 & 3 & & & & 3 & & & & \\
\hline Daring & 9 & 3 & 9 & & & & & & & 9 \\
\hline Persuasion & 9 & & & & & 3 & & & 9 & 9 \\
\hline Commitment & 3 & 9 & 3 & 9 & 9 & 3 & 3 & 3 & 3 & 9 \\
\hline Believe & 9 & 9 & 9 & & 3 & 3 & & & & 9 \\
\hline Proactivity & 9 & 3 & 3 & 9 & 9 & 9 & 3 & 3 & 9 & 9 \\
\hline Search for support & 9 & 1 & 3 & & 3 & 9 & 3 & & 9 & 3 \\
\hline
\end{tabular}

Source: Prepared by the authors.

According to Ribeiro et al. (2001), if the majority of relationships in the matrix are weak, the matrix should be revised, since the quality characteristics are not adequately translating the quality demanded by the clients. And, if there are any items of the demanded quality that do not relate to any item of the entrepreneurial skill, special attention must be taken to identify other entrepreneurial skill that relate to them.

The importance of each quality characteristic (10j) was then determined by Equation 2, which considers the indexes of priorizeted quality (IDi*) and the correlation indexes (DQij), as suggested by Ribeiro et al. (2001):

$I Q j=\sum_{i=1}^{n} \frac{I D i^{*} \cdot D Q i j}{100}$

It is noteworthy that the relationship of the quality demanded with the quality characteristics is good since most of the research relationships have 84 strong correlations and 66 medium correlations. However, one point to be observed is the high number of quality demands that do not correlate with the quality characteristics (60 occurrences), but should not prejudice the current analysis. 
In the sequence, it was evaluated the difficulty of acting on the quality characteristics (Dj), that is, the difficulty of modifying the specifications of the quality characteristics. A scale of 0.5 to 2.0 (0.5, very difficult; 1.0, difficult; 1.5, moderate; and 2.0, easy).

A competitive assessment was also performed, comparing the current specifications of the company's quality characteristics with those of the competitors. The competitive evaluation of the quality characteristics (Bj), a technical benchmarking, was performed similarly; using a range of 0.5 to 2.0 ( 0.5 - above the competition, 1.0 - similar to the competition, 1.5 - below the competition and 2.0 - well below the competition) was used.

The prioritization of the quality characteristics (1Qj*) is performed through the corrected importance index. It allows identifying what are the characteristics that, if developed, will have a greater impact on customer satisfaction. This index was calculated using Equation 3, suggested by Ribeiro et al. (2001).

$I Q j^{*}=I Q j \cdot \sqrt{D j} \cdot \sqrt{B j}$

Table 3 shows the QFD Quality Matrix region called the projected quality, which details the importance of each quality characteristic (1Qj), the difficulty of acting on the quality characteristics (Dj), the competitive evaluation $(\mathrm{Bj})$ and the prioritization of quality characteristics (1Qj*).

Table 3. Prioritization of quality characteristics $\left(10 \mathrm{j}^{*}\right)$.

\begin{tabular}{|c|c|c|c|c|c|c|c|c|c|c|}
\hline & 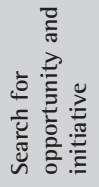 & 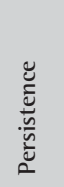 & 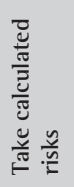 & 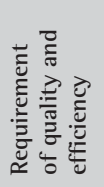 & 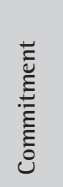 & 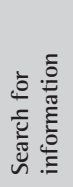 & 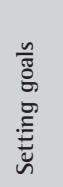 & 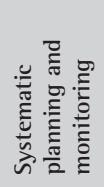 & 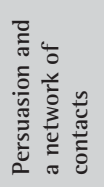 & 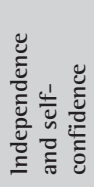 \\
\hline Importance of QC (1Qj) & 8.35 & 5.25 & 4.12 & 3.93 & 6.16 & 6.23 & 5.62 & 4.27 & 7.42 & 7.94 \\
\hline Difficulties evaluation(Dj) & 0.5 & 1.0 & 1.0 & 1.5 & 1.0 & 1.5 & 1.0 & 1.0 & 1.0 & 0.5 \\
\hline Competitive evaluation (Bj) & 1.0 & 1.0 & 1.0 & 1.5 & 1.5 & 1.0 & 1.0 & 1.5 & 1.5 & 2.0 \\
\hline Prioritization (1Qj*) & 5.91 & 5.25 & 4.12 & 5.89 & 7.54 & 7.63 & 5.62 & 5.23 & 9.08 & 7.94 \\
\hline
\end{tabular}

Source: Prepared by the authors.

It may be seen in Table 3 before the analysis including ( $\mathrm{Dj}$ ) and (Bj), the characteristics of the most important quality $(1 \mathrm{Qj})$ were: "Search for opportunity and initiative", with $1 \mathrm{Qj}=8,35$, "Independence and self-confidence", with $1 \mathrm{Qj}=7.94$, and "Persuasion and network of contacts", with $1 \mathrm{Qj}=7.42$. The characteristic of the least important quality (1Qj) was "Requirement of quality and efficiency", with $1 \mathrm{Qj}=3.93$.

The prioritization of the quality characteristics $\left(1 \mathrm{Qj}^{*}\right)$, which was calculated using the weights attributed to the difficulty of performance (Dj) and technical benchmarking (Bj), shows that the most important quality characteristics after the correction were: "Persuasion and network of contacts ", with $1 \mathrm{Q} j$ " $=9.09$; "Independence and self-confidence", with $1 \mathrm{Qj}^{*}=7.94$, and "Search for information", with $1 \mathrm{Qj}{ }^{*}=7.63$. The characteristic with the least corrected quality $\left(1 \mathrm{Qj}^{*}\right)$ was "Take calculated risks", with $1 \mathrm{Qj}^{*}=4,12$.

It is interesting to see how the use of factors that may influence their prioritization of characteristics involved in the table may change the order of importance of these characteristics, through the QFD procedure.

Table 4 shows the complete QFD Quality Matrix for the case in question.

Table 4. Complete QFD Quality Matrix.

\begin{tabular}{|c|c|c|c|c|c|c|c|c|c|c|c|c|c|c|}
\hline & $\ddot{E}$ & 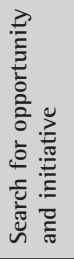 & 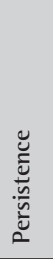 & 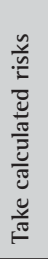 & 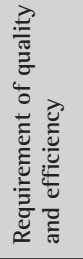 & 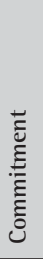 & 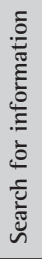 & 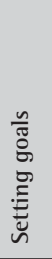 & 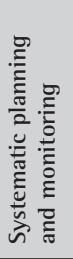 & 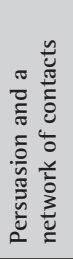 & 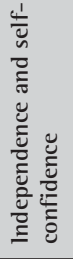 & 近 & $\bar{\Sigma}$ & $\stackrel{*}{\underline{\underline{E}}}$ \\
\hline Focus & 4.78 & 9 & 9 & 3 & 3 & 3 & 9 & 9 & 9 & 3 & 9 & 2.0 & 1.5 & 8.28 \\
\hline Knowledge search & 4.71 & 3 & 3 & 9 & 3 & & 9 & 9 & 9 & 3 & 3 & 2.0 & 1.0 & 6.66 \\
\hline
\end{tabular}

$\mathrm{DDi}^{*}=$ prioritization of quality items demanded. Source: Prepared by the authors. 
Table 4. Coontinued...

\begin{tabular}{|c|c|c|c|c|c|c|c|c|c|c|c|c|c|c|}
\hline & $\ddot{\underline{e}}$ & 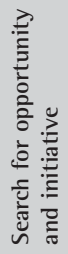 & 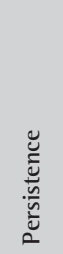 & 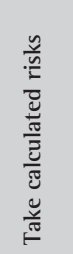 & 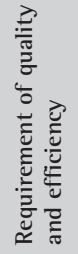 & 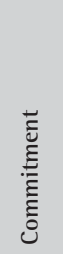 & 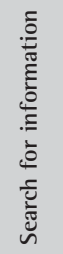 & 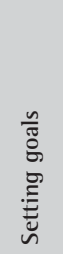 & 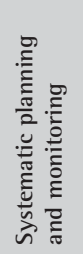 & 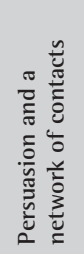 & 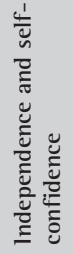 & iت & $\ddot{\Sigma}$ & $\stackrel{*}{\ominus}$ \\
\hline Entrepreneurship & 4.26 & 9 & 9 & 9 & 9 & 9 & 9 & 9 & 9 & 9 & 9 & 2.0 & 1.5 & 7.38 \\
\hline Organization & 4.69 & 3 & 3 & 3 & 9 & 3 & 3 & 9 & 9 & 3 & 3 & 2.0 & 1.5 & 8.12 \\
\hline Honesty & 4.69 & & & & 3 & 3 & & 1 & & 3 & 3 & 2.0 & 1.0 & 6.63 \\
\hline Unity & 4.59 & & & & & 9 & & & & 9 & 3 & 2.0 & 1.0 & 6.49 \\
\hline Humility & 4.17 & & & & & 9 & 9 & 1 & & 3 & 1 & 0.5 & 1.0 & 2.95 \\
\hline Leadership & 4.15 & 9 & 3 & 3 & & 9 & 3 & 9 & 1 & 9 & 9 & 2.0 & 1.5 & 7.19 \\
\hline Communication & 4.74 & 9 & 3 & 1 & & 3 & 3 & 3 & 1 & 9 & 9 & 2.0 & 1.0 & 6.70 \\
\hline Group work & 4.84 & 3 & & & & 9 & 3 & & 1 & 9 & 9 & 2.0 & 1.0 & 6.84 \\
\hline Developing people & 4.24 & & & & & 9 & & 1 & & 9 & 3 & 1.0 & 1.5 & 5.19 \\
\hline Creativity & 4.72 & 9 & 9 & 3 & & & 3 & 3 & & 3 & 3 & 2.0 & 0.5 & 4.72 \\
\hline Planning & 4.80 & 9 & 9 & 9 & 9 & 3 & 3 & 9 & 9 & 3 & 9 & 2.0 & 1.0 & 6.79 \\
\hline Effort & 4.78 & 9 & 9 & 3 & 9 & 9 & 9 & 9 & 9 & 3 & 9 & 2.0 & 0.5 & 4.78 \\
\hline Good relations / networking & 4.35 & 9 & 3 & 1 & & 3 & 9 & 3 & & 9 & 3 & 2.0 & 1.5 & 7.53 \\
\hline Agility & 4.20 & 9 & 3 & & & & 3 & & & & & 1.5 & 1.5 & 6.30 \\
\hline Daring & 4.07 & 9 & 3 & 9 & & & & & & & 9 & 2.0 & 0.5 & 2.88 \\
\hline Persuasion & 4.37 & 9 & & & & & 3 & & & 9 & 9 & 2.0 & 1.0 & 6.18 \\
\hline Commitment & 4.85 & 3 & 9 & 3 & 9 & 9 & 3 & 3 & 3 & 3 & 9 & 2.0 & 0.5 & 4.85 \\
\hline Believe & 4.87 & 9 & 9 & 9 & & 3 & 3 & & & & 9 & 1.5 & 0.5 & 4.22 \\
\hline Proactivity & 4.54 & 9 & 3 & 3 & 9 & 9 & 9 & 3 & 3 & 9 & 9 & 2.0 & 0.5 & 4.54 \\
\hline Search for support & 4.59 & 9 & 1 & 3 & & 3 & 9 & 3 & & 9 & 3 & 2.0 & 1.0 & 6.49 \\
\hline Importance of QC (1Qj) & & 8.35 & 5.25 & 4.12 & 3.93 & 6.16 & 6.23 & 5.62 & 4.27 & 7.42 & 7.94 & & & \\
\hline Difficulties evaluation (Dj) & & 0.5 & 1.0 & 1.0 & 1.5 & 1.0 & 1.5 & 1.0 & 1.0 & 1.0 & 0.5 & & & \\
\hline Competitive evaluation (Bj) & & 1.0 & 1.0 & 1.0 & 1.5 & 1.5 & 1.0 & 1.0 & 1.5 & 1.5 & 2.0 & & & \\
\hline Prioritization (1Qj*) & & 5.91 & 5.25 & 4.12 & 5.89 & 7.54 & 7.63 & 5.62 & 5.23 & 9.08 & 7.94 & & & \\
\hline
\end{tabular}

$1 \mathrm{Di}^{*}=$ prioritization of quality items demanded. Source: Prepared by the authors.

\section{Final considerations}

From the obtained results, it may be concluded that the World Café method proved to be effective as an auxiliary tool to reveel the needs of the clients of a project, in this case, the students of the class in question, whose result of the conversations brought a great amount of information. The method allowed to establish the most important personal characteristics needed to develop the pedagogical projects of the Logistics course, from the point of view of the students. With the QFD method, the prioritizations of these personal characteristics from the point of view of the students (clients) and from the point of view of the school (designer) were established.

The World Café proved to be an easy-to-apply and low-cost methodology. The inexperience of the students with the methodology did not inhibit the success of its utilization.

Considering the seven principles of the World Café, it has been found to be a highly customer-centred method that is useful for conducting an in-depth exploration of challenges, sharing knowledge, stimulating innovative thinking, building a community and exploring possibilities around themes and real-life issues.

Therefore, the World Café method fulfilled the objective established by Cheng \& Melo Filho (2007) for the qualitative techniques to know the Voice of the Customer: to produce a list of needs that are as wide as possible, with the mind free of preconceived ideas, seeking to learn by simply listening and observing the participants.

The analysis of correlations of the QFD method enabled the researchers to analyze which personal characteristics raised by students had a greater correlation with the characteristics of the entrepreneurial behavior proposed by Lizote \& Verdinelli (2014). It also made it possible to verify which of them had a weak or non-existent correlation. The personal characteristics "Union", "Agility", "Developing people", "Daring" and "Persuasion", should be analyzed with less priority by the faculty, since they presented the lowest correlation indexes. This result 
will allow to teachers of the project discipline a more effective choice of methodologies and teaching-learning practices that stimulate the development of entrepreneurial behaviors.

With the calculation of the prioritization of quality characteristics (1Qj*), it may be concluded that teachers should use pedagogical practices that prioritize the development of entrepreneurial behaviors: "Persuasion and a network of contacts", "Independence and self-confidence" and "Search for information ". It will be these behaviors that, if developed by the students during the discipline, will provide better satisfaction to themselves.

The researchers conclude that the entrepreneurial behavior "Take calculated risks" was ranked last after prioritization since the pedagogical proposal of the projects for a logistics course does not prioritize this characteristic. Therefore, in the view of the researchers, there is no need for students to prioritize the development of this behavior.

This is a typical contribution of the QFD method, by establishing priorities involving characteristics related to the Voice of the Customer. This does not necessarily mean that QFD is always able to determine the best prioritization, since its results are also affected, in some degree, by statistical random elements, but, in any case, it represents an objective and rational way of arriving at least close to an adequate statement for the prosecution of appropriate actions, in each case.

As the authors have not found in the literature the application of the World Café method integrated to QFD, it may be concluded that the present study brought an innovation in the use of the World Café method as a tool to better know the Voice of the Customer. In addition, the study shows an interesting contribution of the World Café and QFD methods to the development of Project-Based Learning (ABPj). It is also expected that the detailed presentation of the calculations performed with the data used in the QFD matrix have contributed to a better understanding of this technique.

Considering the above, it is concluded that the objective of the study was reached. It is recommended in future study to perform the complete construction of the Matrix of Processes of the QFD method, to specify the most effective teaching-learning methods in the development of the entrepreneurial behaviors proposed by Lizote \& Verdinelli (2014).

\section{References}

Barbosa, L., \& Hoffmann, V. (2013). Incubadora de empresas de base tecnológica: percepção dos empresários quanto aos apoios recebidos. Review of Administration and Innovation, 10(3), 208-229. http://dx.doi.org/10.5773/rai.v10i3.973.

Brian Hwarng, H., \& Teo, C. (2001). Translating customers' voices into operations requirements: a QFD application in higher education. International Journal of Quality \& Reliability Management, 18(2), 195-226. http://dx.doi.org/10.1108/02656710110379075.

Broom, M., Brady, B., Kecskes, Z., \& Kildea, S. (2013). World Café Methodology engages stakeholders in designing a Neonatal Intensive Care Unit. Journal of Neonatal Nursing, 19(5), 253-258. http://dx.doi.org/10.1016/j.jnn.2012.12.002.

Brown, J., \& lsaacs, D. (2007). The World Café: dando forma ao nosso futuro por meio de conversações significativas e estratégicas (1st ed.). São Paulo: Cutrix.

Cervo, A. L., \& Bervian, P. A. (2002). Metodologia cientifica (5th ed.). São Paulo: Prentice Hall.

Chang, W. (2016). Online training for business plan writing through the World Café method: the roles of leadership and trust. Universal Access in the Information Society, 16(2), 313-324. http://dx.doi.org/10.1007/s10209-016-0459-y.

Chang, W., \& Chen, S. (2015). The impact of World Café on entrepreneurial strategic planning capability. Journal of Business Research, 68(6), 1283-1290. http://dx.doi.org/10.1016/j.jbusres.2014.11.020.

Cheng, L., \& Melo Filho, L. (2007). QFD: desdobramento da função qualidade na gestão de desenvolvimento de produtos (1st ed.). São Paulo: Blucher.

Costa Neto, P., \& Canuto, S. (2010). Administração com qualidade: conhecimentos necessários para a gestão moderna (1st ed.). São Paulo: Blucher.

Delors, J. (2006). Educação: um tesouro a descobrir (10th ed.). São Paulo: Cortez.

Freitas, L., Melo Filho, L., Cheng, L., \& Carmo, M. (2015). Análise da aplicação do método desdobramento da função qualidade “QFD” em serviços preventivos de polícia. Revista Produção Online, 15(1), 243. http://dx.doi.org/10.14488/1676-1901.v15i1.1774.

Kempnich, J., \& Costanzo, C. (2014). World Café for leadership development. Nurse Leader, 12(6), 98-101. http://dx.doi.org/10.1016/j. mnl.2014.05.016.

Kokotsaki, D., Menzies, V., \& Wiggins, A. (2016). Project-based learning: a review of the literature. Improving Schools, 19(3), $267-277$. http://dx.doi.org/10.1177/1365480216659733.

Lagrosen, Y. (2017). The Quality Café: developing the World Café method for organisational learning by including quality management tools. Total Quality Management \& Business Excellence. In press. http://dx.doi.org/10.1080/14783363.2017.1377606.

Lefika, P., \& Mearns, M. (2015). Adding knowledge cafés to the repertoire of knowledge sharing techniques. International Journal of Information Management, 35(1), 26-32. http://dx.doi.org/10.1016/j.jinfomgt.2014.09.005.

Lizote, S., \& Verdinelli, M. (2014). Relação entre competências empreendedoras e desempenho: um estudo em empresas prestadoras de serviços contábeis. Revista de Contabilidade e Organizações, 8(22), 49. http://dx.doi.org/10.11606/rco.v8i22.55605. 
Ribeiro, J. L. D., Echeveste, M., \& Danilevicz, A. M. F. (2001). A utilização do QFD na otimização de produtos, processos e serviços. Porto Alegre: FEENG/PPGEP/EE/UFRGS.

Silva, M. (2003). Educação online: teorias, práticas, legislação, formação corporativa. São Paulo: Loyola.

Souza, V., \& Cauchick Miguel, P. (2017). Aplicação do desdobramento da função qualidade em serviços: uma análise da literatura. Revista Produção Online, 17(1), 268. http://dx.doi.org/10.14488/1676-1901.v17i1.2519.

Teza, P., Miguez, V., Fernandes, R., de Souza, J., Dandolini, G., \& de Abreu, A. (2013). Geração de ideias: aplicação da técnica World Café. International Journal of Knowledge Engineering And Management, 3(3), 1-14.

Thiollent, M. (1986). Metodologia da pesquisa-ação. São Paulo: Cortez.

Yankeelov, P., Faul, A., D’Ambrosio, J., Gordon, B., \& McGeeney, T. (2018). World cafés create healthier communities for rural, older adults living with diabetes. Health Promotion Practice, 152483991876055. http://dx.doi.org/10.1177/1524839918760558. PMid:29557175. 